\title{
P-072 I \\ ANNUAL DIRECT MEDICAL COSTS OF OUTPATIENTS \\ WITH DIABETIC FOOT DISEASE IN BRAZIL
}

\section{Sugita TH'; Bahia LR²; Quarti M²; Rosa R³, Toscano CM' \\ I-Federal University of Goias, Goiania, Goias, Brazil}

2- State University of Rio de Janeiro, Rio de Janeiro, Brazil

3-Federal University of Rio Grande do Sul, Porto Alegre, Rio Grande do Sul, Brazil

\section{an array of medical}

Background: Diabetic foot disease (DFD) includes an array of medical
conditions, mainly resulting from diabetic peripheral neuropathy and arterial disease which can lead to foot ulceration, wound infection, osteomyelitis and, ultimately, amputation. As a result, DFD burden is significant, resulting in major economic consequences for patients, their families and society. Limited evidence on the costs of treating diabetic foot is available, in particular in developing countries, where its burden is higher.

Aims: To estimate the annual direct medical costs of outpatients with Diabetic foot disease in Brazil, in 2014.

Method: A cost-of-illness study was conducted considering the perspective of the Brazilian Public Health Care System (SUS). The analytic horizon was one year (2014). Only medical costs were considered.

Considering the range of syndromes included in the DFD spectrum, we developed four well-defined hypothetical DFD cases:

l) neuroischemic foot without ulcer;

2) non-infected foot ulcer;

3) infected foot ulcer;

4) clinical management of amputated patients (Figure I)

DFD conditions requiring hospitalization, i.e., osteomyelitis, and amputations were not considered.

A panel of 12 experts in DFD from various reference centers in the country were invited to participate and answer a standardized questionnaire of resource utilization.

Healthcare resources used were quantified, and then multiplied by unit costs according to the National Pricing List. Then, the costs were extrapolated to obtain the annual direct medical costs of DFD outpatients in Brazil as a whole, considering a decision tree based on epidemiologic parameters obtained from the national literature (basecase) and using national/international parameters for sensibility analysis (Table I).

Costs were estimated in Brazilian Reais (BRL) and then converted to USD (IUSD=2.66 BRL) and Int $\$$ (IBRL=I.7477, World Bank) using official conversion rates for 2014 .

Table I Epidemiologic parameters for the base-case and sensitivity analysis. Extrapolation of annual direct medical costs of DFD outpatients in Brazil - 2014

\begin{tabular}{lc|c|c}
\hline & Base-case & \multicolumn{2}{c}{$\begin{array}{c}\text { Sensitivity } \\
\text { analysis }\end{array}$} \\
\cline { 2 - 4 } Parameters & $\%$ & Minor \% & Major \% \\
\hline $\begin{array}{l}\text { Self-reported prevalence of diabetes } \\
\text { Prevalence of DFD among individual }\end{array}$ & 6.2 & - & - \\
with diabetes & 9 & 3.3 & 10.6 \\
Proportion of diabetic patient with ulcer & 5.3 & 1.24 & 30 \\
Proportion of outpatient treated ulcer * & 98.3 & 65.2 & 99.7 \\
$\quad$ - Proportion of non-infected ulcer & 50 & 88.0 & 44.5 \\
$\quad-$ Proportion of infected ulcer & 50 & 12.0 & 55.5 \\
$\begin{array}{l}\text { Proportion of patient which required } \\
\text { amputation }\end{array}$ & 1.4 & 1,1 & 13.7 \\
\hline
\end{tabular}

\footnotetext{
* Estimated based on the proportion of inpatient treatment of infected ulcer.
}

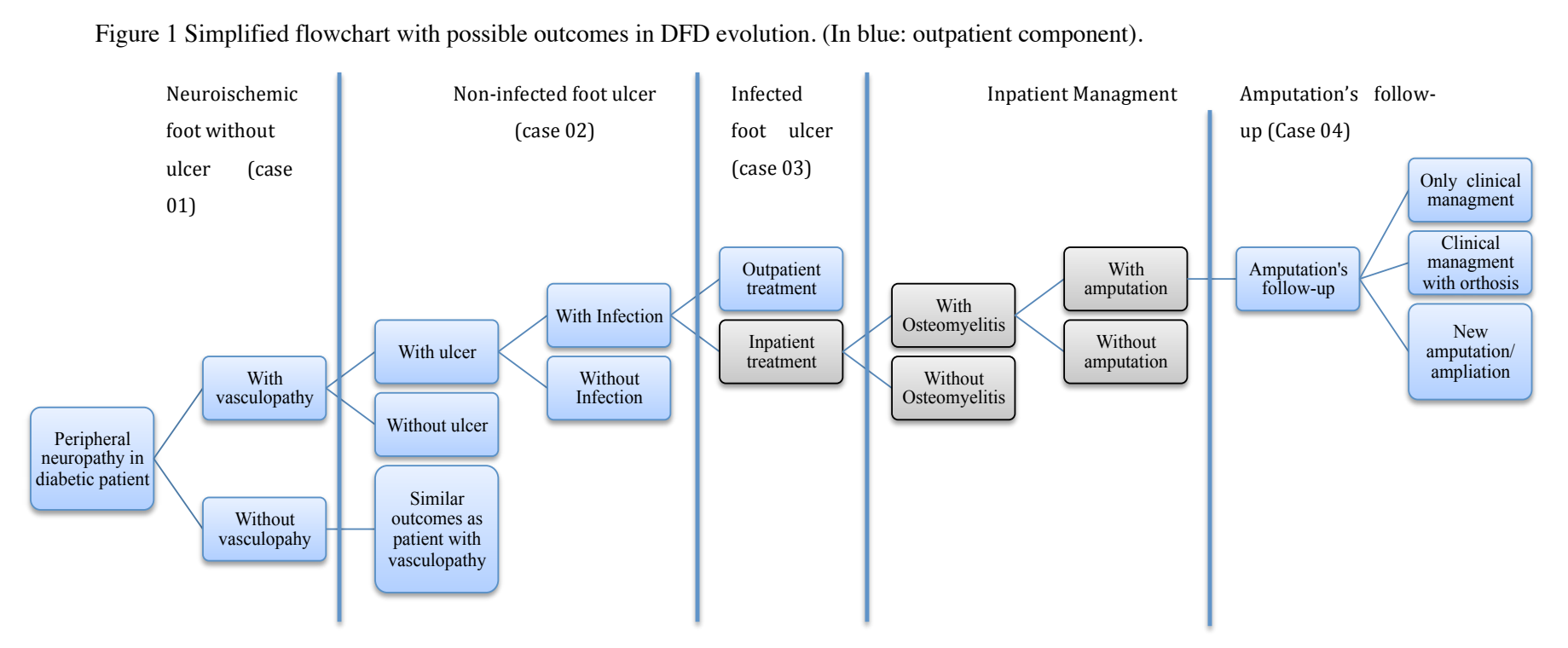

Results: The average annual direct medical costs were estimated at USD 225.8 (Int $\$ 343.7$ ) for a case of peripheral neuropathy without ulcer, USD 268.2 (Int\$ 408.I) for a case of non-infected foot ulcer, USD I,062.5 (Int\$ I,6I7.I) for a case of infected foot ulcer, and USD 394.I (Int\$599.7) for the clinical management of an amputated patient (Table 2). The most relevant cost component was healthcare professionals (16-38\%), followed by the imaging exams (8-40\%).

As a result of the extrapolation the estimated number of diabetic individuals with diabetic foot disease $(829,7$ thousand), foot ulcers $(43,726)$, infected ulcers $(21,49 I)$, and amputated $(11,284)$ resulted in an estimated total outpatient annual direct medical costs of USD 220.43 million (Int\$ 335.49 million) (Table 4).

Table 2 Costs of annual direct medical costs of the four hypothetical DFD outpatients cases - 2014

\begin{tabular}{lccc}
\hline Cases & $\mathrm{BRL}( \pm \mathrm{SD})$ & $\begin{array}{c}\text { Cost per case } \\
\mathrm{USD}( \pm \mathrm{SD})\end{array}$ & $\ln \$( \pm \mathrm{SD})$ \\
\hline Neuroischemic foot & $600.7( \pm 183.3)$ & $225.8( \pm 68.9)$ & $343.7( \pm 104.9)$ \\
without ulcer & & & \\
Non-infected foot ulcer & $713.3( \pm 501.6)$ & $268.2( \pm 188.6)$ & $408.1( \pm 287.0)$ \\
Infected foot ulcer & $2,826.1( \pm 2,063)$ & $1,062.5( \pm 775)$ & $1,617( \pm 1,180.8)$ \\
Amputation's follow-up & $1,048.2( \pm 498.1)$ & $394.1( \pm 187,3)$ & $599.8( \pm 285)$ \\
\hline
\end{tabular}

Table 3 Costs of annual direct medical costs of DFD outpatients. Basecase and Sensitivity Analysis - 2014

\begin{tabular}{|c|c|c|c|c|}
\hline \multirow{3}{*}{ Cases } & \multicolumn{4}{|c|}{ Value in (Int\$) } \\
\hline & \multirow{2}{*}{ Base-case } & \multirow{2}{*}{$\%$} & \multicolumn{2}{|c|}{ Sensitivity analysis } \\
\hline & & & minor & major \\
\hline $\begin{array}{l}\text { Neuroischemic foot } \\
\text { without ulcer }\end{array}$ & $285,197,634$ & 85,0 & $104,572,466$ & $335,899,436$ \\
\hline Non-infected foot ulcer & $8,771,481$ & 2,6 & 833,409 & $53,085,828$ \\
\hline Infected foot ulcer & $34,752,922$ & 10,4 & 477,286 & $262,319,121$ \\
\hline Amputation's follow-up & $6,767,704$ & 2,0 & $2,007,088.8$ & $80,294,609$ \\
\hline Total & $335,489,743$ & 100 & $107,940,251$ & $731,598,996$ \\
\hline
\end{tabular}

Table 4 Costs of annual direct medical costs of DFD outpatients in Brazil, total and per outcome - 2014

\begin{tabular}{lccc}
\hline Cases & \multicolumn{3}{c}{ Total cost } \\
\hline Neuroischemic foot & $498,439,906$ & $187,383,423$ & $285,197,634$ \\
without ulcer & $15,329,918$ & $5,763,127$ & $8,771,481$ \\
Non-infected foot ulcer & $60,737,683$ & $22,833,715$ & $34,752,922$ \\
Infected foot ulcer & $11,827,916$ & $4,446,585$ & $6,767,704$ \\
Amputation's follow-up & $586,335,424$ & $220,426,851$ & $335,489,743$ \\
\hline Total &
\end{tabular}

Conclusion: Little evidence is available on the economic burden of DFD in Brazil. Significant resource utilization for the outpatient management DFD syndromes, particularly related to healthcare personnel were identified. Costs were higher for more severe disease. This significant health and economic burden for the Brazilian Healthcare System emphasis the need for health policies targeting its improved prevention and care.

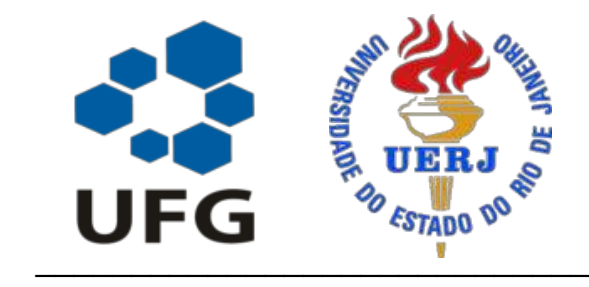

